\title{
INFLUENCE OF RIDING EXPERIENCE ON GLANCE BEHAVIOR, BRAKE RESPONSE TIME AND DECELERATION RATES BY DRIVERS AND MOTORCYCLISTS
}

\author{
Jeffrey Muttart ${ }^{1}$, Donald Fisher ${ }^{1}$, Chris Kauderer ${ }^{2}$, Wade Bartlett ${ }^{3}$, Louis Peck ${ }^{4}$, \\ Steve Guderian ${ }^{5}$, Lisa Ton ${ }^{6}$, \& Matthew Muttart ${ }^{6}$ \\ ${ }^{1}$ University of Massachusetts, Amherst, Massachusetts, USA \\ ${ }^{2}$ Kauderer \& Associates, Sacramento, California, USA \\ ${ }^{3}$ Mechanical Forensic Engineering Services, Rochester, New Hampshire, USA \\ ${ }^{4}$ SD Lyons, Inc., Seekonk, Massachusetts, USA \\ ${ }^{5}$ San Francisco Municipal Transportation Authority \& Motorcycle Safety Consulting, \\ San Francisco, California, USA \\ ${ }^{6}$ Crash Safety Solutions, LLC, Uncasville, Connecticut, USA \\ Email: Muttartj@gmail.com
}

\begin{abstract}
Summary: The focus of the research was to address the crash avoidance behaviors of drivers versus motorcyclists. Avoidance tasks include, attention maintenance and hazard anticipation measured with glance behaviors, and hazard mitigation measured with response times and deceleration. Specifically, where might the driver behavior be similar or different than that of a motorcyclist? The performances of 23participants were analyzed while they drove a car and rode a motorcycle over the same low-volume, open roads. Participants wore eye-tracking equipment used to record eye-glance information while the motorcycle and car were instrumented with an on-board accelerometer and GPS apparatus. Operators also responded by braking quickly to a stop when an LED, mounted in front of them, was illuminated. Motorcyclists spent less time glancing toward the road ahead and made fewer last-glances toward the direction of most threatening traffic before turning when riding the motorcycle, as opposed to when driving a car. Additionally, motorcyclists' response times were similar to those when driving, yet motorcyclists decelerated less sharply compared to drivers. These results suggest that riders may be exposing themselves to unnecessary risk. Specifically, motorcyclists frequently failed to make proper glances and practice optimal riding techniques. The implication of these results relative to a training curriculum is discussed.
\end{abstract}

\section{INTRODUCTION}

\section{The Problem}

According to the Fatal Accident Reporting System (Fatal Accident Reporting System, 2008), there were 38,444 fatal crashes in 2004. Motorcycles were involved in 4,100 of those crashes. In 2008, the total number of fatal crashes dropped $11.5 \%$ (34,017), yet fatal motorcycles crashes increased $31.4 \%(5,387)$. The current research examined the differences in the avoidance behaviors of skilled riders when driving a car and riding a motorcycle. The influence of age and years licensed were also analyzed. 


\section{Contributions to the Problem}

Crash avoidance entails three segments: attention maintenance, hazard anticipation, and risk mitigation (Fisher, 2008). Explained a different way, drivers must keep their eyes on the road, anticipate hazards that may or may not materialize, and respond appropriately to potential and immediate hazards. The current study was an examination of the behaviors that are prerequisites of crash avoidance. Motorcyclists have been known to make several more glances toward the pavement for road debris (Nagayama, et al., 1979). In the current research, glances off the road or at the pavement immediately ahead of the vehicle were measures of failures of attention maintenance. Pradhan et al. (2005) measured hazard anticipation of experienced and novice drivers by noting the glances made to the left and right for cross traffic when entering an intersection. The current research extends the research by Pradhan et al. to motorcyclists. Lastly, risk mitigation will be measured by the brake response time [BRT] and deceleration of the participants when driving and riding a motorcycle.

\section{Research Goals}

The immediate goal of the research was to determine where motorcyclists might differ from drivers in crash avoidance behaviors. This was a first step in the process. With this information, targeted research can be planned in areas of attention maintenance, hazard anticipation, risk mitigation, and training. Specifically, this research investigated the abilities of motorcyclists and drivers, of different ages and experience, to keep their eyes on the road ahead, anticipate hazards at intersections, and respond and stop for hazards. With the information from this research, training curricula and more targeted research may be planned.

\section{METHODOLOGY}

\section{Participants}

Members of the research team recruited 23 drivers/motorcyclists through advertisements in Motorcycle Consumer News and by word of mouth. Participants included 17 males and six females with ages ranging from 20 to 69 years. Of these participants, six obtained a motorcycle license or endorsement within the previous five years, 13 have been licensed or endorsed for six to 19 years and 13 were licensed for 20 or more years.

\section{Equipment}

The experimental vehicles included a 2008 Kawasaki Ninja 650R and a 2009 Dodge Charger. Vericom 4000 tri-axial accelerometers were mounted on-board each vehicle. On the motorcycle, string potentiometers monitored front and rear brake use. In the car, string potentiometers recorded accelerator and brake pedal displacement.

A 2009 Mercury Marquis was used as the lead vehicle for both rider and driver experiments. Four LEDs were mounted on top of a stalk, which was in turn mounted to the windshield of the motorcycle or car. The top two LEDs were red and the bottom two LEDs were amber. The red LEDs were used as the cue to implement a hard braking maneuver, and were activated by a 
wireless system controlled by an experimenter in the lead vehicle. The amber lights signified the need to turn left or right. The amber signals were not used for this portion of the research.

\section{Procedure}

After signing the informed consent, each participant completed a questionnaire regarding riding experience, training, and the type of motorcycle normally ridden. The questionnaire was also used to verify that confounding factors such as drug use or health issues did not negatively influence participants’ performances.

Each participant was fitted with the ASL MobileEye eye-tracking system. The experimenter provided helmets that accommodated the eye-tracking system to those drivers who could not fit the eye tracking glasses under their own helmets.

Each participant drove both the car and the motorcycle for approximately 25 minutes. The order in which participants drove or rode was randomly assigned. The layout of the course and the location of each of these intersections are shown in Figure 1 and described in Table 1.

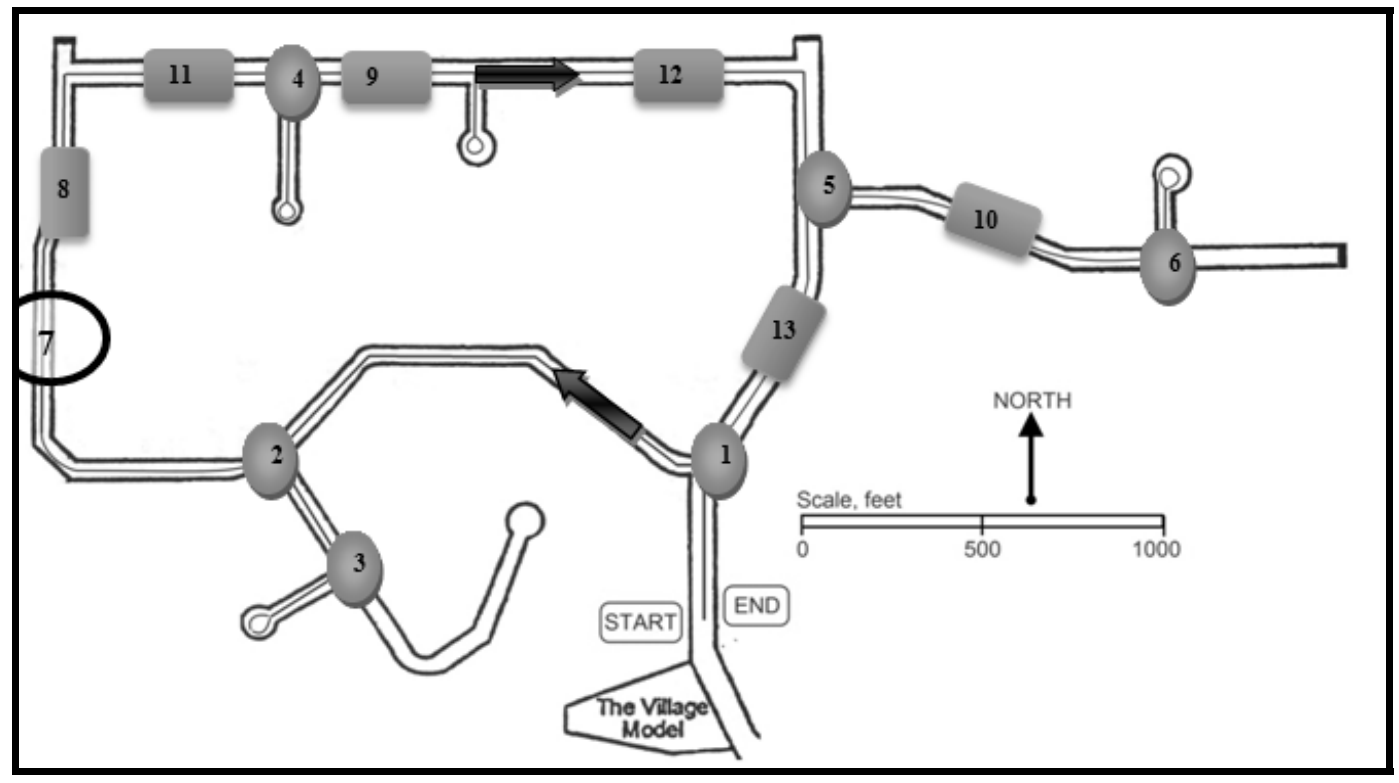

Figure 1. Scale diagram of the test site with the data collection stations marked

During both the motorcycle and car portions of the experiment, the participants traveled one twomile sighting lap to familiarize themselves with the car or motorcycle, followed by four laps through the course during which data were collected. Therefore, each participant traveled the course ten times, five on a motorcycle and five in a car. 
Table 1. Description of station numbers

\begin{tabular}{|c|c|}
\hline Station number & Data collected \\
\hline $1,3,4,6$ & Right turn at the end of the lap - does the driver/rider make a glance ahead. \\
\hline 2,5 & Glance for opposing traffic when turning left into side road, from the main road. \\
\hline $2,3,5$ & $\begin{array}{l}\text { When exiting side road, (1) did the driver make a glance to the right when approaching the stop line and (2) } \\
\text { did they make a glance to the left after starting forward? }\end{array}$ \\
\hline $1,3,4,6,7$ & Right turn - did the driver/rider make a glance at the pavement when turning or when crossing sandy road? \\
\hline $8,9,10$ & Locations where LED was illuminated and pedestrians are present at both roadsides. \\
\hline $11,12,13$ & Locations where LED was illuminated and pedestrians were not present. \\
\hline $9,11,12$ & Locations where road glances were recorded \\
\hline
\end{tabular}

\section{Definition of Variables and Methods to Collect the Information}

Glance Measures: Attention Maintenance and Hazard Anticipation. Attention maintenancerelated glance behaviors fell into two categories, pavement glances before entering an intersection, and time looking away from the road ahead on a straight road segment. When making right turns at four locations, and at one location with sand on the road, if the driver or rider glanced toward the pavement within one car length ahead of their vehicle, a pavement glance was recorded. If no such glance was made, no glance was recorded.

On straight road segments, time spent fixating areas beyond the road edges was recorded. Percent time glancing off the road was defined as the time the driver looked at a position that is more than seven degrees left or right of straight ahead. It should be noted, for any driver looking three seconds ahead of their vehicle the road edges are no more than seven degrees left or right of straight ahead. For instance, if a driver is positioned 14 feet from the road edge and looking three-seconds ahead while traveling $30 \mathrm{mph}$, the road edge would be six degrees to the right. The percent time glancing off the road was defined as the percent of the time the operator made fixations at a position beyond seven degrees left or right.

Hazard anticipation glances at intersections involved a determination of whether the operator made a glance toward the closest potential hazard location at the moment, or after, the vehicle starts its turn. Scoring of glances was similar to the methodology by Pradhan, et al. (2005).

Brake Response Times [BRT]. BRTs were measured from the activation of a red LED to the first application of a brake. For riders, the first application of a brake could be the rear or front brake.

Deceleration rate. Participants were told to respond to the LED lights mounted to the windshield of both the motorcycle and passenger car. When the red LEDs illuminated, they were to stop as quickly as possible while maintaining their safety. Deceleration was measured by the accelerometer by noting the speed loss over the time from the start of the response until stopped.

Driver and Rider Experience. Experience was defined in terms of driver age and years licensed. Driver age was divided into two categories: those under age 25 years or over age 25 . The 25-year threshold was selected to conform to the age, at which fatal crash rates level off to that of middle-aged drivers (Mayhew, 2003). Years licensed was divided into two categories as well: those licensed or endorsed for fewer than four years or more than five years. 


\section{RESULTS}

\section{Attention Maintenance and Hazard Anticipation}

A within subject repeated measure ANOVA was utilized to test the effects of both mode of transportation and measure of hazard. There were two transportation mode factors (motorcycle and car). There were five potential hazard glance measures. Two involve attention maintenance; pavement glances and percent time glancing at a position greater than seven degrees left or right of straight ahead. The remaining three potential hazards address hazard anticipation; a) left turn across path, opposite direction [LTAP], b) right turns, and c) left turns. LTAP-OD occurred when the turning driver is traveling on the major street and turns across a conflicting lane or lanes of traffic. Table 2 shows the results when driving versus riding a motorcycle and the significance is shown in Table 3. The mode of transportation was a significant factor for glances toward hazards (Figure 3). Age was not associated with a significant change in glance behaviors. A Bonferroni adjustment for multiple comparisons was applied and showed that left turn glances were significantly different than LTAP-OD $(\mathrm{SE}=0.71, \underline{\mathrm{P}}=0.001)$, right turn $(\mathrm{SE}=0.71, \underline{\mathrm{P}}=$ 0.14 ), and pavement glances ( $\mathrm{SE}=0.91, \underline{\mathrm{P}}=0.024)$.
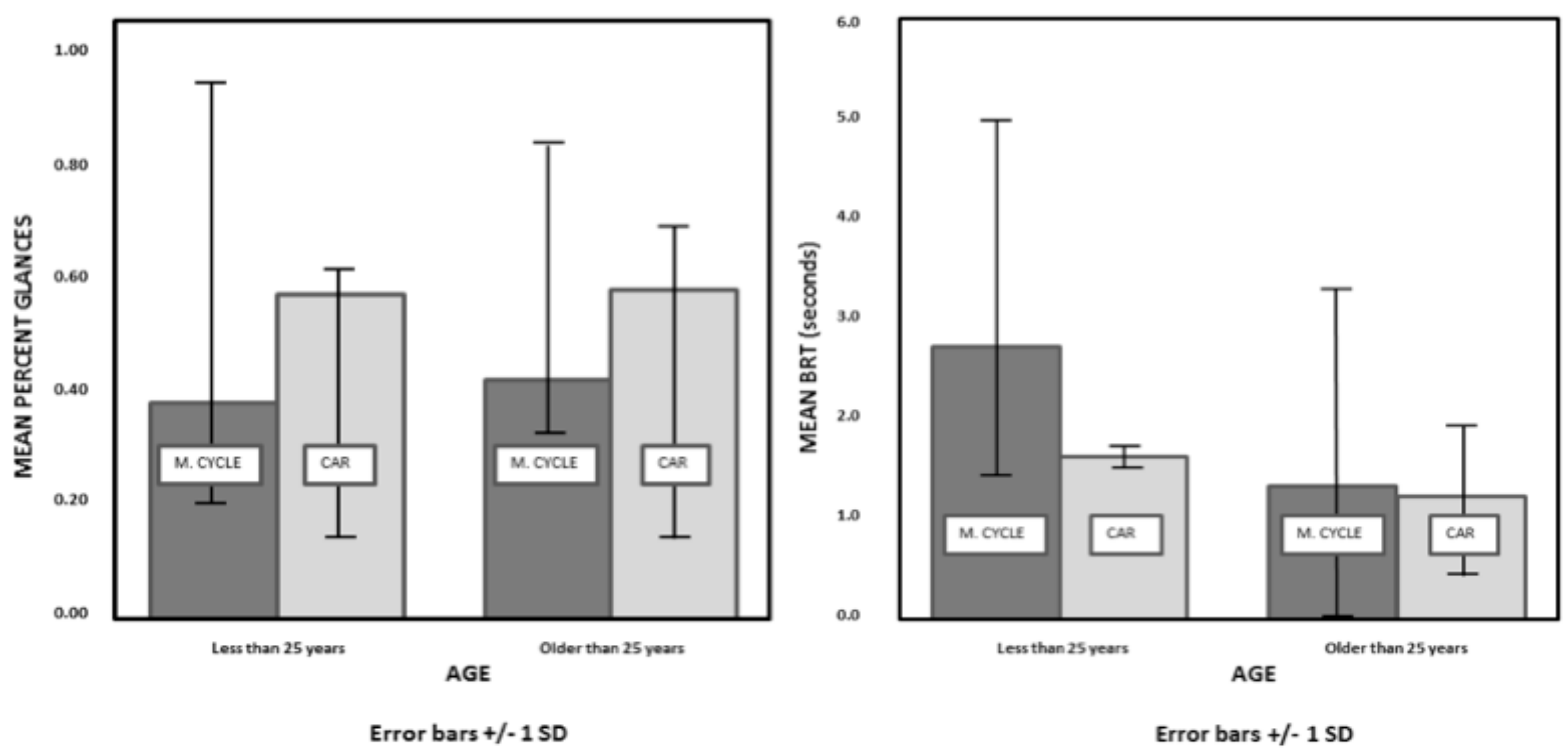

Figure 3. Probability of a last glance toward the greatest threat for operators older and younger than 25 (left); BRT of operators less than and more than 25 while driving and riding (right)

Table 2. Summary of results from the participants while driving a car or riding a motorcycle

\begin{tabular}{|c|c|c|c|c|c|c|}
\hline & \multicolumn{3}{|c|}{ Car } & \multicolumn{3}{|c|}{ Motorcycle } \\
\hline & $\mathrm{N}$ & Percent & SD & $\mathrm{N}$ & Percent & SD \\
\hline Glance turns & 283 & $60 \%$ & $32 \%$ & 270 & $42 \%$ & $33 \%$ \\
\hline Glance pavement & 112 & $50 \%$ & $33 \%$ & 99 & $73 \%$ & $28 \%$ \\
\hline Glance off road & 22 & $8.1 \%$ & & 22 & $21.8 \%$ & \\
\hline Deceleration & 31 & 0.55 Gs’ & 0.12 Gs’ & 50 & 0.44 Gs’ & $0.10 \mathrm{Gs}$ \\
\hline Time to brake & 19 & $1.14 \mathrm{~s}$ & $0.55 \mathrm{~s}$ & 37 & $1.26 \mathrm{~s}$ & $1.06 \mathrm{~s}$ \\
\hline Stop & 119 & $66 \%$ & $37 \%$ & 109 & $39 \%$ & $36 \%$ \\
\hline
\end{tabular}




\section{Risk Mitigation (response and braking)}

For BRTs and deceleration factors, there were two threat conditions (pedestrians present, and pedestrians absent). The mode of transportation was a significant factor for BRT (Table 2), and deceleration rate. Younger and older drivers and older motorcyclists had similar BRTs, with young riders needing nearly one second more to respond. Young participants and experienced riders decelerated similarly and experienced drivers decelerated at a rate that was $0.18 \mathrm{Gs}$ ' greater than other groups. Younger motorcyclists were significantly slower to respond than drivers of any age or motorcyclists over age 25.

Regarding braking, riders braked less aggressively at locations where pedestrians were present, and drivers decelerated more aggressively overall, which caused the Mode x Measure interaction to be significant. Although, older drivers decelerated at a greater rate, the difference was not significant.

Table 3. Statistical significance from the repeated measure ANOVA

\begin{tabular}{|c|c|c|c|c|c|c|}
\hline & \multicolumn{2}{|c|}{ Gs’ } & \multicolumn{2}{|c|}{ BRT } & \multicolumn{2}{|c|}{ Glances } \\
\hline & $F(1,23)$ & $\mathrm{P}$ & $\mathrm{F}(1,23)$ & $\mathrm{P}$ & $\mathrm{F}(1,23)$ & $\mathrm{P}$ \\
\hline Measures & 0.26 & 0.62 & 0.12 & 0.74 & 13.96 & 0.00 \\
\hline Measure x age & 0.30 & 0.59 & 0.03 & 0.87 & 0.86 & 0.37 \\
\hline Measure x yrs licensed & 1.79 & 0.21 & 0.08 & 0.79 & 2.57 & 0.13 \\
\hline Mode & 12.00 & 0.00 & 6.90 & 0.04 & 9.95 & 0.01 \\
\hline Mode $\mathrm{x}$ age & 1.09 & 0.32 & 5.86 & 0.05 & 0.05 & 0.84 \\
\hline Mode x yrs. licensed & 0.03 & 0.87 & 0.57 & 0.48 & 0.05 & 0.83 \\
\hline Mode x Measure & 5.13 & 0.04 & 0.39 & 0.55 & 0.59 & 0.46 \\
\hline Mode x Measure x age & 0.13 & 0.73 & 0.09 & 0.78 & 3.96 & 0.07 \\
\hline Mode x Measure x yrs. licensed & 0.01 & 0.93 & 0.03 & 0.86 & 1.82 & 0.20 \\
\hline
\end{tabular}

Note: Values in bold and italics indicate statistical significance

\section{DISCUSSION}

\section{Attention Maintenance}

Related to attention maintenance (eyes on the road ahead), nearly one in four motorcyclists' glances were in areas beyond the road edge. Also, motorcyclists made half as many more glances toward the pavement immediately ahead of their motorcycle.

When making a turn, motorcyclists must be able to monitor traffic within an intersection and must also inspect the road surface for anomalies that may contribute to a loss of control. According to Klauer (2006, p.104), “...drivers involved in crashes had their eyes off the forward roadway a significantly longer portion...than did those drivers involved in near-crashes or incidents." Applied to these results, there is evidence that motorcyclists are exposing themselves to greater crash risk. 


\section{Hazard Anticipation}

Drivers in this research made anticipatory intersection glances very much as Pradhan et al (2005) predicted. However, motorcyclists made 18\% fewer glances toward the area of greatest threat (nearest vehicle or shortest sightline) after starting a turn and before entering conflicting traffic. Some riders failed to glance in the direction of potential conflicting traffic for as much as five seconds before starting a turn. In posttest interviews, many riders claimed to be taught to "follow-their-nose" through a turn. While such a tactic may assist in rider control, riders should make a last anticipatory glance immediately before following those noses through the turn.

\section{Risk Mitigation (Responding)}

Young motorcyclists were much slower to respond than all other operators. Motorcycle braking performance was $80 \%$ of that when driving a car, with riders over the age of 25 performing slightly better, and those under age 25 performing slightly worse. The current study measured the performance of a rather experienced group of participants at a specific location and on a specific motorcycle. If the experience, test location and motorcycle are changed, the results may differ.

The results of the current study suggest that young (and novice) riders should be targeted for training. Training should include attention maintenance (keeping one's eyes on the road), hazard anticipation (looking for potential hazards that may not be visible) and braking more efficiently in response to hazards.

\section{ACKNOWLEDGMENTS}

We would like to gratefully acknowledge the support of Kawasaki Motor Corp., USA, SATAI, the Bullhead City Police Department of Arizona, and to McCormick Realty for allowing us to test on the roads at their Desert Canyon at Sunridge property. This research was funded by the Rider Response Evaluation Team (http://riderresponse.com/index.html) and by a grant to Donald Fisher from the National Institutes of Health (R01HD057153). Its contents are solely the responsibility of the authors and do not necessarily represent the official views of NIH.

\section{REFERENCES}

National Highway Traffic Safety Administration (2008). Fatal Accident Reporting System. Washington, D.C.: Retrieved May 10, 2010, http://www.nhtsa.gov/people/ncsa/fars.html.

Fisher, D. L. (2008). Evaluation of PC-Based Novice Driver Risk Awareness. Washington, DC: National Highway Traffic Safety Administration.

Klauer, S.G., Dingus, T. A., Neale, V. L., Sudweeks, J.D., and Ramsey, D.J. (2006). The Impact of Driver Inattention on Near-Crash/Crash Risk: An Analysis Using the 100-Car Naturalistic Driving Study Data. DOT HS 810 594, Washington, DC; National Highway Traffic Safety Administration.

Nagayama, Y., et al. (1979). Motorcyclists' visual scanning pattern in comparison with automobile drivers'. Warrendale, PA : Society of Automotive Engineers, 790262. 
PROCEEDINGS of the Sixth International Driving Symposium on Human Factors in Driver Assessment, Training and Vehicle Design

Pradhan, A.K., Hammel, K.R., DeRamus, R., Pollatsek, A., Noyce, D.A., \& Fisher, D.L. (2005). The use of eye movements to evaluate the effects of driver age on risk perception in an advanced driving simulator. Human Factors, 47, 840-852. 